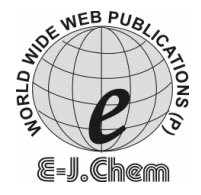

http://www.e-journals.net
ISSN: 0973-4945; CODEN ECJHAO

E-Journal of Chemistry

2009, 6(2), 504-510

\title{
Evaluation of ATC as an Orally Administered Drug in Treatment of Cadmium Toxicity of Rat Organs
}

\author{
S. NABILALDINE FATEMI, SOLMAZ TUBAFARD, \\ S. JAMILALDINE FATEMI ${ }^{*}$ and BEHNAM NADI \\ Department of Chemistry, Shahid Bahonar University, Kerman, Iran. \\ fatemijam@yahoo.com
}

Received 10 June 2008; Revised 5 July 2008; Accepted 1 August 2008

\begin{abstract}
The effect of $N$-tetramethylene dithiocarbamate (ATC) as a chelating agent on the excretion of cadmium was evaluated in cadmium-poisoned Wistar rats following administration through food and drink. The present research aimed to characterize the potential efficiency of ATC as an orally administered chelator drug after cadmium administration for 60 days. This chelator significantly enhanced the urinary and biliary excretion of cadmium and restored the altered levels of iron. Cadmium and iron concentrations in different tissues were determined by graphite furnace and flame atomic absorption spectrometry (GF AAS and F AAS) methods, respectively. The chelation therapy results show that ATC is able to remove cadmium ions from different tissues while iron concentration returned to the normal level and the clinical symptoms were also reduced. In summary, we conclude that ATC is able to mobilize and promote the excretion of cadmium in rat organs and reduce the side effects and general symptoms of toxicity caused by cadmium and might be useful for preliminary testing of the efficacy of chelating agents in human body. However, these results should be confirmed in different experimental models before extrapolation to other systems. This testing procedure of course does not provide all the relevant answers for evaluating the efficiency of chelating agents in cadmium toxicity.
\end{abstract}

Keywords: Ammonium $N, N$ tetramethylene dithiocarbamate (ATC), Cadmium toxicity, Chelation therapy, Rat

\section{Introduction}

Cadmium is unique among non-essential metals in its numerous toxicological effects because of its long biological half life, slow excretion and delayed action on the kidneys ${ }^{1}$. Although cadmium poisoning in humans is uncommon, there are reports of 
chronic cadmium poisoning in workmen and also in general population in certain polluted areas $^{2}$. At present there are no suitable methods either to measure the body burden of cadmium or to treat cadmium poisoning. Symptoms and signs in humans after excessive exposure to cadmium usually involve the gastrointestinal tract after single oral intake, the lung after acute inhalation and the kidney after long-term exposure ${ }^{3}$. These organs are usually considered to be the "critical" organs, i.e., the organs are mostly sensitive at a certain type of exposure. The kidney is considered to be the most sensitive organ to long-term exposure to cadmium. Although this type of cadmium-induced damage does not frequently occur in the general population, a high incidence has been reported in some population groups in areas where food and drinking water have been contaminated with cadmium. Consequently, extensive studies have been carried out to identify the mechanisms of cadmium toxicity ${ }^{4.5}$. Although information regarding the primary intracellular sequences of cadmium toxicity is still lacking, it is now well established that liver and kidney are the major target of cadmium toxicity ${ }^{6,7}$.

Cadmium is an industrial product or by-product which is of environmental concern. It is used in many industrial processes, such as a constituent of easily fusible alloys, soft solder, electroplating and deoxidizer in nickel plating, engraving processes, electrodes for vapor lamps, photoelectric cells, and nickel-cadmium storage batteries ${ }^{8}$. Therefore, there can be many industrial hazards due to this element. Concentration of cadmium has been reported to be higher in air of industrial cities, thus providing a possible environmental hazard 9 . Cadmium poisoning has been reported from foods which had been kept or prepared in cadmium-plated containers and has occasionally been found in drinking water in unacceptable levels. Cadmium, in contrast to many other elements, accumulates with age in tissues ${ }^{10}$. Very little renal cadmium is present at birth, but relatively large amounts of this element are present in kidneys of adults ${ }^{11}$, the concentration of which in newborns being less than $1 \%$ of that in adults. Therefore, this pattern is suggestive of environmental exposure ${ }^{12}$. In fact, it has been claimed that approximately one-third of the cadmium accumulated in the body of an adult was absorbed during the first few years of life.

Cadmium is more readily taken up by plants than other metals, such as lead. Factors contributing to the presence of cadmium in the soil are fallout from the air, cadmium-containing water used for irrigation, and cadmium present in fertilizers ${ }^{13}$. A number of cadmium-induced effects including deterioration of cell-cell adhesion, DNA- related processes; cell signaling and energy metabolism can imply that this metal acts on the different molecular targets in human organs. It is shown that cadmium can induce apoptosis in mouse liver ${ }^{14,15}$. Occupational exposures occur mainly through the respiratory route, but also involve the gastrointestinal route to a lesser degree ${ }^{16,17}$. The therapeutic effects of various chelating agents including 2, 3dimercaptopropanol (BAL) and its soluble glycosides have been studied without much success in acute cadmium intoxication. ${ }^{18}$ consequently, there is a continual search for finding a new cadmium chelating agent with improved properties, particularly activity when administered orally. Chelation therapy involves the use of ligating drugs that binds metal for the treatment of potentially fatal conditions. These ligands promote the excretion and subsequent depletion of this transition metal in biological systems ${ }^{19}$. These chelating agents consist of a range of bidentate, tridentate and hexadentate ligands in which two, three or six atoms, are able to coordinate respectively ${ }^{19,20}$. It is a medical treatment in which a chelator is added to the blood through a vein or oral administration in order to remove harmful metals from the body.

The aim of this study is to test the chelation potency of ATC as an orally administered drug given to animals after cadmium loading. Testing was performed by using an acute experimental model on rats. Then chelation therapy by ATC was investigated to find out whether this chelator 
could mobilize and promote the removal of cadmium in rat organs. To our knowledge no such study of cadmium and ATC given concurrently, has been done previously.

\section{Experimental}

\section{Reagent}

Ammonium $N, N$ tetramethylene dithiocarbamate(ATC) and $\mathrm{CdCl}_{2} \cdot \mathrm{H}_{2} \mathrm{O}$ purchased from Merk. Nitric acid $\left(\mathrm{HNO}_{3} 65 \%\right)$ supra pure and hydrogen peroxide $\left(\mathrm{H}_{2} \mathrm{O}_{2} 30 \%\right)$ were used for oxidation and digestion of organic materials.

\section{Instrument}

A microwave oven Model CEM MDS 200 was used to remove the water content present in organs and facilitate digestion. Atomic absorption spectrometer (F AAS and GF AAS) Model Varian was used for measurement of cadmium and iron concentrations in organs respectively. Also an analytical balance Model Mettler AE 160 was used in this study

\section{Maintenance of the animals}

Male Wistar rats nearly 60 days old were obtained from Pastor Institute of Karaj, Iran. They were bred in animal house of the department of biology in Shahid Bahonar University. The rats were maintained under a controlled light: dark $(12: 12 \mathrm{~h})$ schedule at $23 \pm 1^{\circ} \mathrm{C}$. The animals were kept in well cleaned sterilized cages. The rat food was purchased from Karaj Institute, Tehran. This study was approved by the ethics committee of the Bahonar University, Kerman, Iran.

\section{Experimental design}

In our model, we used two different doses of cadmium followed by an early administration of chelating agent. Cadmium at two doses of 20 and $40 \mathrm{mg} / \mathrm{kg}$ body weight were given to animals.

In this experiment, animals were classified as follows: Group I (Control): was given normal food and distilled water to drink. Group II: Low dose drinking group $(20 \mathrm{mg} / \mathrm{kg}$ $\left.\mathrm{Cd}^{2+}\right)$. Group III: High dose drinking group $\left(40 \mathrm{mg} / \mathrm{kg} \mathrm{Cd}{ }^{2+}\right)$. Control group consisted of three animals and other groups had nine animals. Oral administration was performed once a day. The dosing volume for animals was calculated based upon their weight. After 60 days cadmium toxicity symptoms appeared. Three animals of each group were randomly selected and named as "before chelation therapy" group. These rats were anesthetized with ether vapors and immobilized by cervical dislocation. Animals were sacrificed by exasanguination from abdominal aorta; and blood, kidney, spleen and heart samples were collected, weighed and dried for determination of cadmium content. The blood samples were allowed to clot and the serum was removed by centrifugation. The samples placed in an oven at $60^{\circ} \mathrm{C}$ for digestion during 3 days. The cadmium content was determined and the results were listed as "before chelation therapy group" in Table 2.

In order to investigate the abilities of ATC in removing cadmium from the body, some studies were carried out on the remaining rats. The animals in each group were divided into two sections: without chelation therapy and with chelation therapy. The second group was administered $100 \mathrm{mg} / \mathrm{kg}$ ATC during one week. At the end of each step, animals were sacrificed by exsanguination from abdominal aorta and several tissues were collected, weighed and dried for determination. The blood samples were allowed to clot and the serum was removed by centrifugation. The samples placed in an oven at $60^{\circ} \mathrm{C}$ for digestion during 3 days $\left(1.5 \mathrm{~mL}\right.$ of $\mathrm{HNO}_{3}$ was added per $1 \mathrm{~g}$ of dry weight). After digestion, the solutions were evaporated with the addition of $1.0 \mathrm{~mL}$ of $\mathrm{H}_{2} \mathrm{O}_{2}$ under the hood. Then, the residue was diluted with water to $100 \mathrm{~mL}$ volume. 


\section{Sampling methodology}

All of the organs were placed into each previously weighed vessel and then dried in the microwave oven. To control the state of dryness of samples the temperature was monitored until samples reached a constant weight. After this procedure, $5 \mathrm{~mL}$ of $\mathrm{HNO}_{3}$ was added per $1 \mathrm{~g}$ of dry weight of organs. After digestion, the solutions were evaporated with the addition of $3 \mathrm{~mL}$ of $\mathrm{H}_{2} \mathrm{O}_{2}$ in the hood until hydrogen peroxide fumes no longer were observed. Solutions prepared in this way were analyzed by AAS using the standard addition method.

\section{Determination of cadmium and iron}

Determination of cadmium and iron in samples were done by GF AAS and F AAS spectrometry, respectively. The values are expressed in mean values for at least three separated determination and their standard deviation.

\section{Results and Discussion}

There were no significant differences between the groups in the initial body weight of the rats (mean $135 \mathrm{~g}$ ), but at the end of cadmium administration experiment, those given cadmium in their diet had weight significantly less (Table 1).

Table 1. Body weights over 60 days for rats in different groups (values are mean for a number of observations in parentheses)

\begin{tabular}{cccc}
\hline Group & Control & $\begin{array}{c}\text { Low level } \\
\text { drinking }\end{array}$ & High level drinking \\
\hline Final body weight, g & $290(10)$ & $225(10)$ & $270(10)$ \\
\hline
\end{tabular}

There was also an effect of dietary treatment on food intake, whereby animals given normal diet, consumed more food than those given cadmium. Results of cadmium and iron increasing in blood and other tissues of two doses groups were statistically different. The cadmium accumulation in tissues at $40 \mathrm{mg} / \mathrm{kg}$ dose was more than the $20 \mathrm{mg} / \mathrm{kg}$ dose. Some of cadmium toxicity symptoms which appeared during the period of cadmium intake were darkening of the eyes, yellowish discoloration of hair, flaccid and hypotonic muscles, irritability, weakness, loss of hair and weight. From the obtained data, it is clear that there is a significant increase of cadmium concentration $(\mathrm{p}<0.05)$ in the different tissues as compared with the control group. The effects of oral administration of the chelator on cadmium and iron concentrations in the various tissues are summarized in Table 2 and 3. Based on the data, the cadmium concentration after chelation therapies with ATC decreased significantly $(p<0.05)$. Spontaneous elimination of cadmium caused by biological system in the group without chelation therapy is not noticeable (Table 2). Furthermore, cadmium accumulation in tissues of treatment group at higher dose levels was more than the lower dose levels.

Table 2. The results of cadmium content in various tissues of rats before and after chelation therapies with ATC are as follows:

Kidney, $\mathrm{mg} / \mathrm{Kg}$

\begin{tabular}{cccc}
\hline Group & $\begin{array}{c}\text { Before chelation } \\
\text { therapy }\end{array}$ & $\begin{array}{c}\text { Without } \\
\text { chelation therapy }\end{array}$ & $\begin{array}{c}\text { Chelation therapy } \\
\text { with ATC }\end{array}$ \\
\hline Control & $0.282 \pm 0.021^{*}$ & $0.280 \pm 0.026$ & $0.193 \pm 0.14$ \\
Low dose drinking group & $0.420 \pm 0.011$ & $0.401 \pm 0.031$ & $0.305 \pm 0.021$ \\
High dose drinking group & $0.780 \pm 0.035$ & $0.758 \pm 0.025$ & $0.312 \pm 0.031$ \\
\hline
\end{tabular}


Blood, $\mu \mathrm{g} / \mathrm{L}$

\begin{tabular}{cccc}
\hline Control & $0.118 \pm 0.011^{*}$ & $0.112 \pm 0.014$ & $0.064 \pm 0.016$ \\
\hline Low dose drinking group & $0.790 \pm 0.015$ & $0.757 \pm 0.016$ & $0.221 \pm 0.0025$ \\
High dose drinking group & $1.185 \pm 0.021$ & $1.161 \pm 0.018$ & $0.255 \pm 0.019$ \\
\hline \multicolumn{3}{c}{ Heart, $\mu \mathrm{g} / \mathrm{kg}$} \\
\hline Control & $0.0391 \pm 0.0026^{*}$ & $0.0386 \pm 0.0029$ & $0.0258 \pm 0.0020$ \\
\hline Low dose drinking group & $0.0560 \pm 0.0023$ & $0.0481 \pm 0.0019$ & $0.0371 \pm 0.0018$ \\
High dose drinking group & $0.0701 \pm 0.0033$ & $0.0676 \pm 0.0021$ & $0.0433 \pm 0.0017$ \\
\hline
\end{tabular}

\begin{tabular}{cccc}
\multicolumn{4}{c}{ Spleen, $\mathrm{mg} / \mathrm{kg}$} \\
\hline Control & $0.318 \pm 0.011^{*}$ & $0.313 \pm 0.017$ & $0.263 \pm 0.013$ \\
\hline Low dose drinking group & $0.790 \pm 0.015$ & $0.778 \pm 0.016$ & $0.328 \pm 0.022$ \\
High dose drinking group & $1.185 \pm 0.021$ & $1.168 \pm 0.018$ & $0.435 \pm 0.019$ \\
\hline
\end{tabular}

$*=S D$ (The number of rats in each group were nine, Results are presented as arithmetic means \pm SEM, significant at $p<0.05$ when compared with control)

The highest amount of cadmium was found in spleen and kidney. After chelation therapy, there is statistical difference among different tissues in each dosage level. The results were found to be in good agreement with the certified values at the $95 \%$ confidence level and also significantly passed the $t$-test. The cadmium concentration of the diet had a significant effect on iron status as assessed by deposited iron in different tissues (Table 3).

Table 3. The results of iron content before and after chelation therapies with ATC.

$$
\text { Blood, mg/L }
$$

\begin{tabular}{cccc}
\hline Group & $\begin{array}{c}\text { Before chelation } \\
\text { therapy }\end{array}$ & $\begin{array}{c}\text { Without } \\
\text { chelation therapy }\end{array}$ & $\begin{array}{c}\text { Chelation therapy } \\
\text { with ATC }\end{array}$ \\
\hline Control & $20.891 \pm 0.211^{*}$ & $20.886 \pm 0.219$ & $18.438 \pm 0.116$ \\
Low dose drinking group & $22.53 \pm 0.119$ & $22.43 \pm 0.211$ & $19.227 \pm 0.310$ \\
High dose drinking group & $24.14 \pm 0.123$ & $24.09 \pm 0.131$ & $21.71 \pm 0.232$ \\
\hline
\end{tabular}

$\begin{array}{rr}\text { High dose drinking group } & 24.14 \pm 0.123 \\ \text { Heart, } \mathrm{mg} / \mathrm{kg}\end{array}$

\begin{tabular}{cccc}
\hline Control & $6.351 \pm 0.111^{*}$ & $6.348 \pm 0.118$ & $5.329 \pm 0.121$ \\
\hline Low dose drinking group & $7.981 \pm 0.210$ & $7.972 \pm 0.231$ & $5.721 \pm 0.130$ \\
High dose drinking group & $9.252 \pm 0.232$ & $9.241 \pm 0.231$ & $6.394 \pm 0.112$ \\
\hline
\end{tabular}

$*=S D$ (The number of rats in each group were nine, Results are presented as arithmetic means \pm SEM, significant at $p<0.05$ when compared with control)

Iron concentration after administration of cadmium significantly increased in blood and heart and not changed greatly in other tissues. Iron increase was more marked in groups consuming the diet with higher cadmium level than in the control one which indicates that cadmium ingestion induces the iron uptake by serum and some organs of rats. The difference between iron content before and after chelation therapy is notable (Table 3).

In order to investigate the effect of passing time in removing cadmium from their body spontaneously, one group was treated "without chelation therapy". The results passed the $t$-test at the $95 \%$ confidence level and were significant in heart among other organs.

Chelation therapy is one of the most effective ways to remove toxic elements from the biological system. In spite of the fact that the efficacy of DFO is well documented, not all 
patients are willing to cope with the rigorous requirements of the long term use of portable pumps. In addition, the high cost of this treatment is a serious obstacle to its more widespread use ${ }^{21}$. In view of these considerations, there is a great need for the development of an alternative orally effective chelating drug. Recently, more than one thousand candidate compounds have been screened in animal models. Along this line, efforts have led to identification of ATC which may have possible clinical usefulness. There has been an increase in exposure to cadmium because of it's presence in fertilizers and sewage sludge and also its increased industrial use in cadmium-Ni batteries. Although there are a number of reports on occupational and environmental exposures to cadmium compounds, treatment of cadmium poisoning has been difficult because there is neither a safe practical mean of evaluating bioavailability body burden nor is there a recommended therapeutic chelating agent for chronic cadmium intoxication ${ }^{22}$. The therapeutic effects of various chelating agents including 2, 3-dimercaptopropanol (BAL) and its soluble glycosides have been studied without much success in acute cadmium intoxication ${ }^{18}$.

The aim of the present work was to characterize the potential toxic effects of cadmium and also to evaluate the ability of ATC as a chelator, in removing cadmium from the body. In this investigation, a short-term experimental model was used in order to speed up the preliminary testing procedure. These results show a direct toxic effect after cadmium administration including such darkening of the eyes, yellowish discoloration of hair, flaccid and hypotonic muscles, irritability, weakness, loss of hair and weight. The effect of chelator on iron level was remarkable. It has been reported that the chelating agents having higher stability constants with a metal in aqueous solution may also prove successful in reducing the body burden of the metal ${ }^{23}$. The high stability constant of cadmium complex could be responsible for its being successful in removing cadmium from the poisoned rats. Uptake of cadmium after oral exposure and gastrointestinal absorption confirmed the accumulation of cadmium in different organs as well as increase of iron concentration in different tissues.

These results show a direct toxic effect of cadmium and also indicate that ATC effectively increases the elimination of cadmium in rats. In order to understand the abilities of the mentioned chelator, we have administrated cadmium salt and observed its accumulation in the liver and other tissues. Administration of the chelating agent was also done early after the administration of cadmium. After chelation therapy, the cadmium content returned to normal level of the control group which indicates that ATC effectively increases the elimination of cadmium in rats and so, greatly decreases the symptom. The comparison of results obtained from the groups "with and without chelation therapy" indicates that physiologic clearance of cadmium was not time-dependent.

In summary, we concluded that ATC could eliminate cadmium from rat organs and treat side effects and general symptoms of toxicity caused by cadmium. Thus, ATC represents a promising drug of cadmium mobilizing agent. Our results show that this procedure might be useful for preliminary testing of the efficiency of chelating agent in removing cadmium. Even though its toxicity is relatively low, basic pre-clinical research is needed before it could be extrapolation to other systems. This testing procedure of course does not provide all the relevant answers for evaluating the efficiency of chelating agents in cadmium toxicity.

\section{Acknowledgement}

The authors are thankful to the Head and Director of International Center of Science, High Technology and Environmental Science, Kerman, Iran. 


\section{References}

1. Friberg L, Piscator M, FOrdberg G, Kjellstrom T, Cadmium in the Environment; Chemical Rubber Co, Cleveland, 1974.

2. $\quad$ Friberg L, Environ Health Persp., 1984, 54, 1-11.

3. Kjellstrom T, Evrin P E and Rahnster B, Environ Res., 1977, 13, 303-317.

4. Shaik Z A and Smith L M, Experientia, 1984, 40, 36.

5. Tohyama C, Sugihira N and Saito H, J Toxicol Environ Health., 1987, 22, 255.

6. Hudecova A E, Food Chem Toxicol., 1992, 30, 1011-1013.

7. Manca D, Richard A C, Trottier B and Chevalier G, Toxicol., 1991, 67, 303-323.

8. Fulkerson W, Goeller H E, Cadmium, The Dissipated Element, Oak Ridge National Laboratory, Oak Ridge, Tenn, 1973.

9. Friberg L, Cadmium in the Environment; $2^{\text {nd }}$ Ed., Press, Cleveland, 1974.

10. Perry H M, Tipton I H, Schroeder H A, Steiner R L and Cook M J, J Chronic Dis., 1961, 14, 259.

11. Schroeder H A and Balassa J J, J Chronic Dis., 1961, 14, 236.

12. Friberg L, Piscator M and Nordberg G F, Cadmium in the Environment; $2^{\text {nd }}$ Ed., CRC Press, Cleveland, 1974.

13. Smolders E,_Int J Occup Med Environ Health., 2001, 14, 177.

14. Shimoda R, Nagamine T, Takagi H, Mori M and Waalkes M P, Toxicol Sci., 2001, 64, 208.

15. Invanoviene L, Staneviciene I, Lesauskaite V, Sadauskien I and Ivanov L, Trace Elem Electroly., 2004, 21, 4-18.

16. Järup L, Berglund M, Elinder C G, Nordberg G and Vahter M, Scand J Work Environ Health., 1998, 24, 1-51.

17. Järup L, Hellstron L and Alfven T, Occup Environ Med., 2000, 57, 668-672.

18. Cherian M G, Nature, 1980, 287, $871-872$.

19. Gomez W, Esparza J L, Domingo J L, Singha P K, Corbella J and Jones M M, Pharmacol Toxicol., 1988, 82, 295-300.

20. Clarke E T and Martell A E, Inorg Chim Acta, 1992, 19, 57-63.

21. Hershko C, Turk J Haematol., 2002, 19(2), 121-126.

22. Jones M M and Cherian M G, Toxicol., 1990, 14, 1-25.

23. Misra M, Athar M, Hasan S K and Srivastava R C, Fund Appl Toxicol., 1988, 11(1), 285-292. 


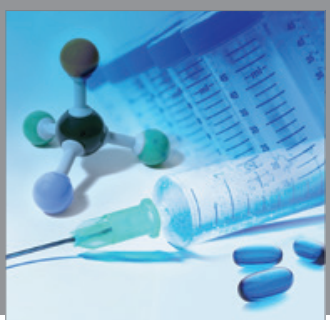

International Journal of

Medicinal Chemistry

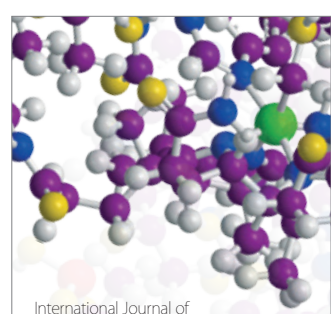

Carbohydrate Chemistry

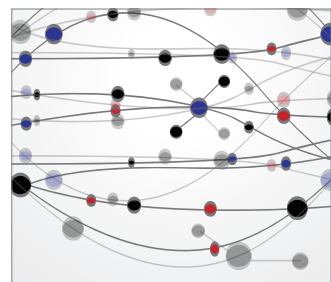

The Scientific World Journal
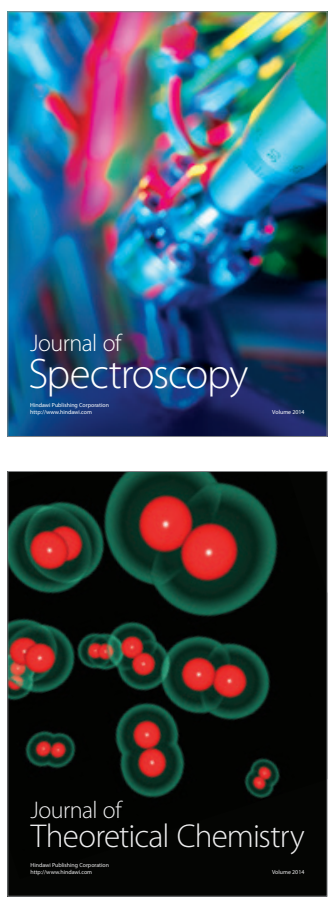
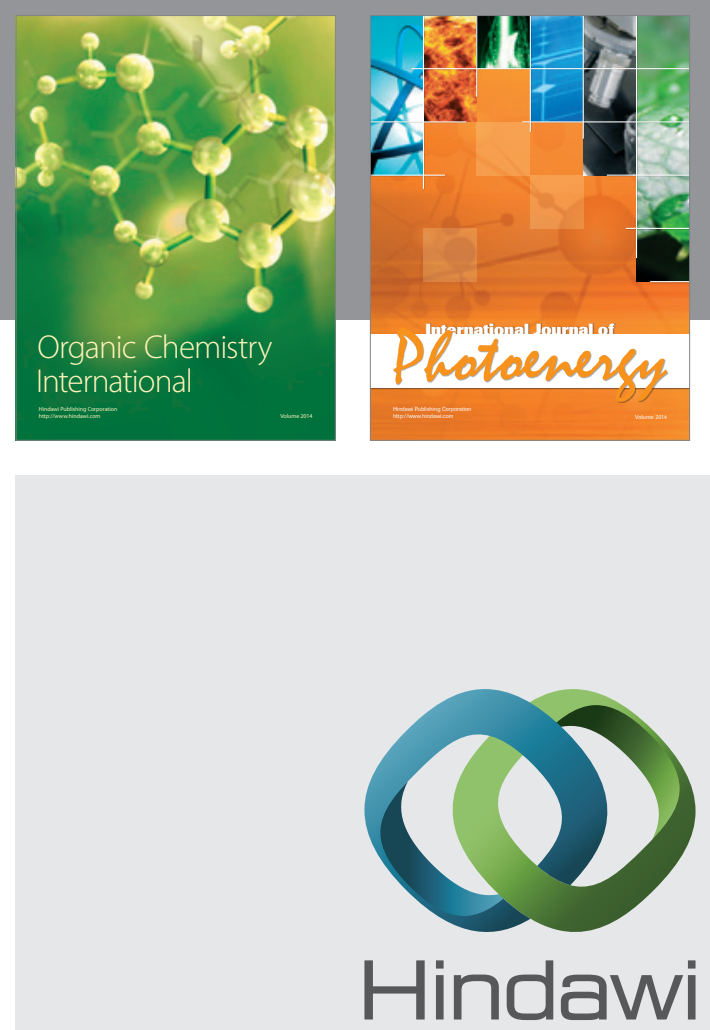

Submit your manuscripts at

http://www.hindawi.com
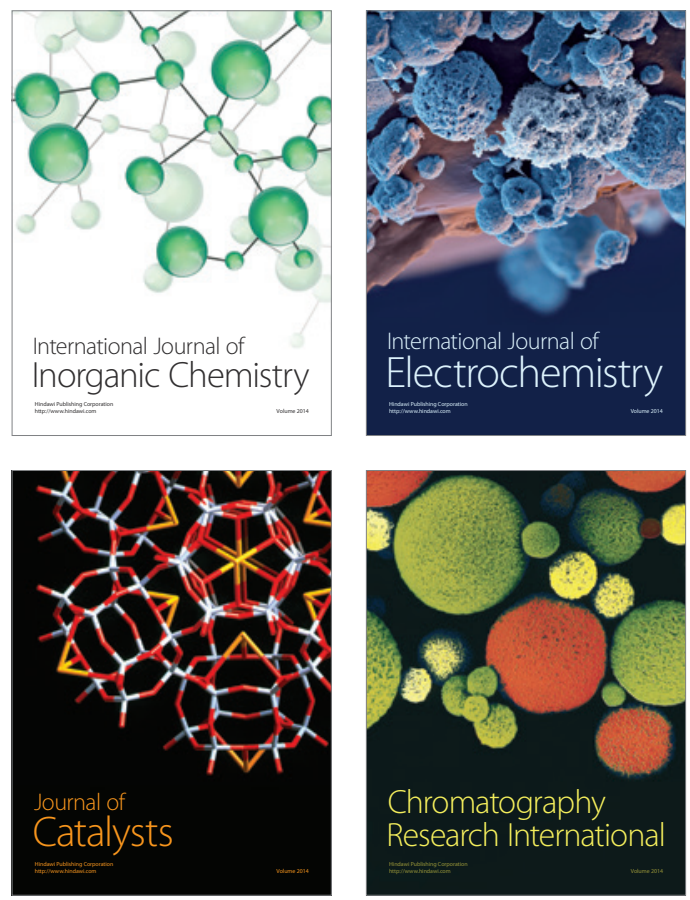
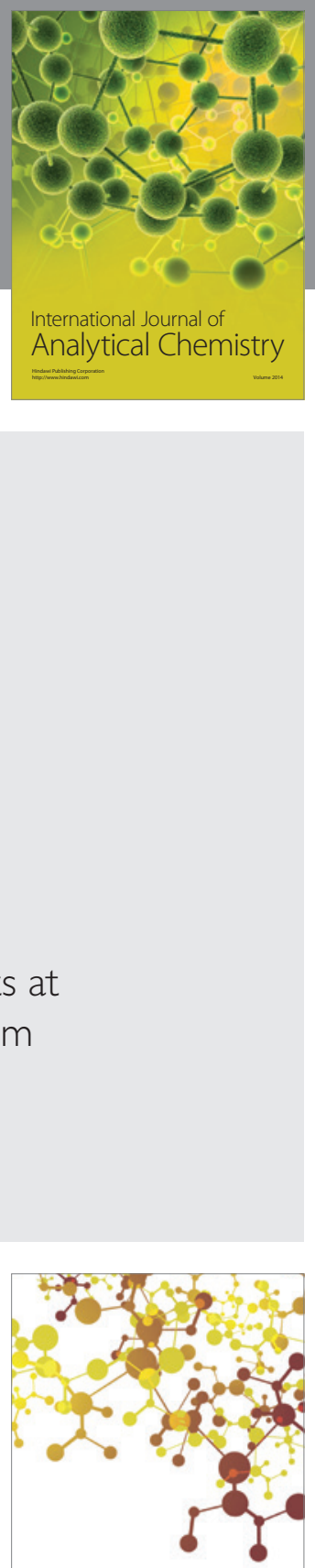

Journal of

Applied Chemistry
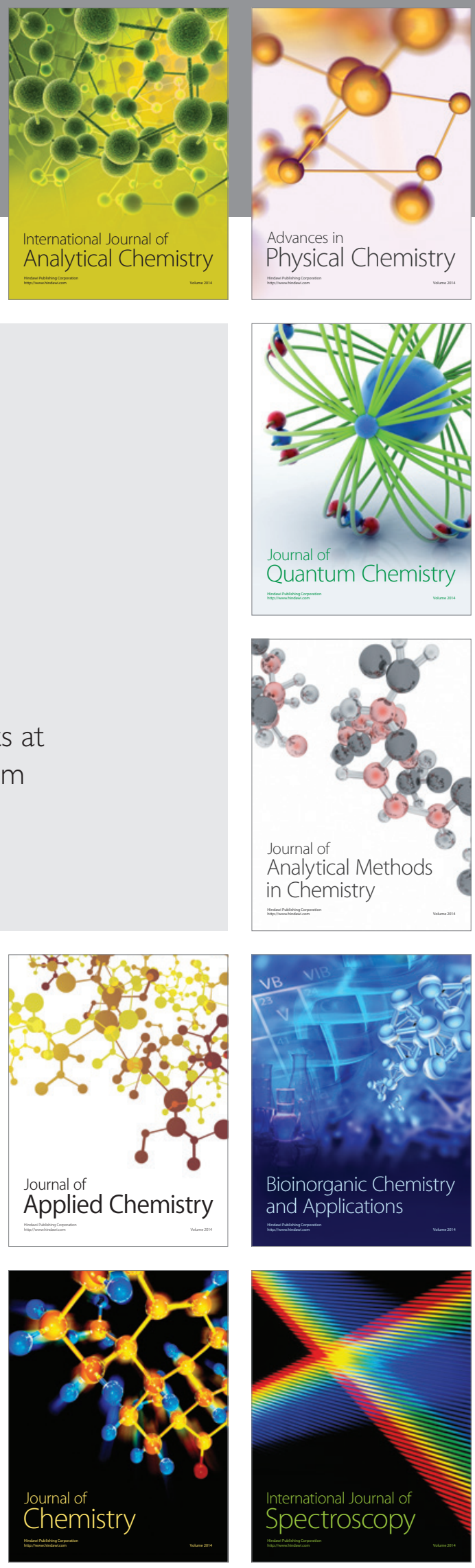